\title{
Product-IT Inclusive Enterprise Architecture Management: An Approach Based on Ecosystems, Customer Journey and Data-Driven Business Opportunities
}

\author{
Julia Kaidalova $^{* 1,3}$, Kurt Sandkuhl ${ }^{1,2}$, and Ulf Seigerroth ${ }^{1}$ \\ ${ }^{1}$ Jönköping University, Box 1026, 55111 Jönköping, Sweden \\ ${ }^{2}$ University of Rostock, Albert-Einstein-Str. 22, 18059 Rostock, Germany \\ ${ }^{3}$ Husqvarna Group AB Group, Drottninggatan 12, 56182 Huskvarna, Sweden \\ julia.a.kaidalova@Husqvarnagroup.com, kurt.sandkuhl@uni-rostock.de, \\ ulf.seigerroth@ju.se
}

\begin{abstract}
Products have evolved from being solely composed of mechanical and electrical parts to complex systems that are connected to the Internet and form the basis for new kinds of functionalities and services. Such smart connected products include a substantial amount of software and information technology which can be called the "product-IT". Enterprise architecture (EA) management is an established function in enterprises providing methods and tools for a systematic alignment of business and IT in an organization. However, EA models capture the details of business, information and technology architecture of an enterprise (i.e., the enterprise-IT) but usually do not include the product-IT. When value creation and delivery in an enterprise's business model also includes the product-IT, a product-IT inclusive view on EA urgently is required. The focus of this article is the methodical support for integration of product-IT and enterprise-IT using enterprise architectures. The main contributions in this article are the conceptual expansion of EA management to become product-IT inclusive that is manifested in a proposal for an extended EA meta-model, and an approach and method components to handle product-IT inclusive EAM.
\end{abstract}

Keywords: Product-IT, Enterprise-IT, Enterprise Architecture, Customer Journey, Ecosystem.

\section{Introduction}

Information technology (IT) is changing products. Products have evolved from being solely composed of mechanical and electrical parts to complex systems of hardware, sensors, data

\footnotetext{
* Corresponding author

(C) 2021 Julia Kaidalova, Kurt Sandkuhl, and Ulf Seigerroth. This is an open access article licensed under the Creative Commons Attribution License (http://creativecommons.org/licenses/by/4.0).

Reference: J. Kaidalova, K. Sandkuhl, and U. Seigerroth, "Product-IT Inclusive Enterprise Architecture Management: An Approach Based on Ecosystems, Customer Journey and Data-Driven Business Opportunities," Complex Systems Informatics and Modeling Quarterly, CSIMQ, no. 26, pp. 1-25, 2021. Available: https://doi.org/10.7250/csimq.2021-26.01
}

Additional information. Author ORCID iD: J. Kaidalova - https://orcid.org/0000-0002-9507-0647, K. Sandkuhl https://orcid.org/0000-0002-7431-8412, and U. Seigerroth - https://orcid.org/0000-0002-5881-0669. PII S225599222100148X. Received: 5 January 2021. Accepted: 15 April 2021. Available online: 30 April 2021. 
storage, microprocessors, software, and connectivity components. Porter and Heppelmann [1] refer to such new products as smart, connected products. Smart, connected products have opened a new era of competition and business value creation. Three core elements of smart, connected products are (1) physical components, (2) "smart" components, and (3) connectivity components [1]. Physical components include mechanical and electrical parts, for instance, engine, batteries and tires in a car. Smart components contain the sensors, microprocessors, data storage, controls, software, an embedded operating system and enhanced user interface. In a car, smart components include the engine control unit, antilock braking system, rain-sensing windshields with automated wipers, and touch screen displays. In many products, software replaces some hardware components or enables a single physical device to perform at a variety of levels. Connectivity components include the ports, antennae, and protocols enabling wired or wireless connections with the product. Smart components increase the capabilities and value of the physical components, whereas connectivity increases the capabilities and value of the smart components and enables some of the smart components to exist outside the physical product itself. Connectivity of smart products sets the foundation for development of huge range of value adding services that are connected to the product. Particularly, product becomes accessible by various components of Product Cloud: smart product applications (services) for monitoring and control; the data regarding the product operation can be stored and analyzed in Product Data Database to reveal new insights; the application platform enables the rapid creation of smart, connected business applications using data access, visualization, and run-time tools [1]. Together, smart components, connectivity components and product cloud shape the digital character of the traditional physical product and form a product-IT, which significantly increase the value of the product.

Examples of transforming from traditional physical product to smart, connected products can be observed in many manufacturing sectors and considered as manifestation of an ongoing digital transformation (DT) [2] (cf. Section 2.1). Enterprises can be affected by DT in various ways, including changes in organizational structure, business processes, information systems, and infrastructure, which together form an Enterprise Architecture (EA). Existing EA frameworks usually define a number of domains or layers that EA includes. TOGAF, for instance, suggests considering layers such as Business, Data, Applications and Technical Architectural domains (cf, Section 2.1). Enterprise Architecture Management (EAM) is a discipline that is traditionally used to address mutual alignment between these domains by taking the embracing view on the overall EA [3] (cf. Section 2.1).

The detailed specifications (models) that represent EA layers and elements are crucial for efficient and structured transformation efforts [4]. EA roadmap and principles can be used as practical instruments for conformity checks and ensures compliance of changed business capabilities [5]. This points out the relevance of EA in the context of DT, including the representation, modeling and management mechanisms and means of methodological support available in EA field. However, for digital transformation EA has to be revised and redefined to account for the broader scope of IT components and resources that DT is addressing - the combination of enterprise-IT and product-IT. Therefore, it is required to redefine EA for the context of DT, where product-IT is included into EA consideration and modeling.

The purpose of this article is to suggest a suitable way for integration of product-IT and enterprise-IT within EA, which currently lacks suitable methodological support. The main contributions in this article are two folded, (1) expansion of established EAM to become product-IT inclusive, and (2) to suggest an approach and method components to handle productIT inclusive EAM.

The outline of this article is as follows. In the next section we present the background for this article in terms of the current state of EAM, digitalization and digital transformation. In Section 3 we present our stance in Design Science Research (DSR) with a case study approach. In Section 4 we describe the empirical work and method requirements for a product-IT inclusive EAM. Section 5 presents our proposal for product-IT inclusive EAM together with suggested 
method components. Section 6 is dedicated to the validation of our approach presented in Section 5. Section 7 summarizes the results.

\section{Background}

\subsection{Enterprise Architecture Management}

In general, an EA captures and structures all relevant components for describing an enterprise, including the processes used for development of the EA as such [6]. EAM provides an approach for a systematic development of an enterprise's architecture in line with its goals by performing planning, transforming, and monitoring functions. The reasons for applying EAM are manifold, such as supporting the alignment of IT to business goals or the reduction of complexity. Organizations have traditionally deployed EAM to help understand, plan, develop, and manage their IT components and resources, i.e., enterprise-IT [5], [7]. By providing a holistic view on business capability elements and their relationships, EAM facilitates translating strategic objectives into business capabilities and concrete changes in business processes, governance structure, and IT components and resources enabling those capabilities and, thus, organizational objectives [4], [5], [8].

The approach for product-IT inclusive EAM presented in this article constitutes a refinement of specific EAM phases and EA modeling languages. More concrete, the approach can be integrated into TOGAF, an EAM approach widely used in industrial practice, and ArchiMate, the modeling language of TOGAF. The remaining part of this section provides an overview to TOGAF and ArchiMate. The refinements that were made to TOGAF and ArchiMate are then the subject of Section 5.

The Open Group Architecture Framework (TOGAF) was developed by members of The Open Group Architecture Forum and provides a detailed description of the phases of IT architecture development. TOGAF offers assistance in the creation of an enterprise architecture by the description of predefined components, the so-called building blocks, and a well-elaborated method, the architecture development method (ADM) [9]. Furthermore, TOGAF is available to any organization that wants to develop an enterprise architecture for its own use. According to TOGAF the enterprise architecture is divided into four partial architectures [10]:

- Business Architecture defines the business strategy, governance, organization and the most important business processes.

- Data Architecture describes the structure of logical and physical data elements and data management resources in the organization.

- Application Architecture defines a design for the individually used application system and its relationship to the core business processes of the organization.

- Technology Architecture describes the software and hardware functions required to support the development of business, data and application services. This includes IT infrastructure, middleware, networks, communication, processing, and standards.

The core of the TOGAF framework is the Architecture Development Method. ADM consists of nine phases that are used to develop an enterprise architecture. This development process is cyclical. For each phase, goals, procedure, required input, activities and results are described [10]. ADM is used iteratively throughout the entire development process. Furthermore, it can be used both between the individual phases and within each phase. ADM describes the viewpoints, techniques and the reference model, but it is not a formal modeling language and does not provide a notation [11]. For this reason, ArchiMate is used together with TOGAF.

ArchiMate is a formal modeling language, including graphical notation [12]. TOGAF and ArchiMate overlap in the use of viewpoints and the concept of an underlying common repository of architectural artifacts and models. The ArchiMate modeling language was developed to provide a uniform representation of for architecture descriptions. It provides an integrated 
architecture approach that describes and visualizes the different architecture domains and their underlying relationships and dependencies. ArchiMate defines three layers as follows [12]:

- Business Layer represents business services offered to customers, which are realized in the organization through business processes executed by business actors.

- Application Layer represents application services that support the business and the applications they implement.

- Technology Layer represents the Technology Services, such as processing, storage and communication services required to run the applications, and the computer and communication hardware and system software that implement these services. Physical elements are included in this layer for modeling physical devices, materials, and distribution networks.

In addition to these layers, the "ArchiMate Core Framework" also defines additional aspects as follows [12]:

- The Active Structure Aspect represents the structural elements. (e.g., business actors, application components and devices that indicate the actual behavior, i.e., the "subjects" of the activity)

- The Behavior Aspect represents the behavior (e.g., processes, functions, events and services) that is executed by the actors. Furthermore, structure items are assigned to behavioral elements to show who or what displays the behavior.

- Passive Structure Aspect represents the objects on which behavior is executed. These are usually information objects in the business layer and data objects in the application layer. Furthermore, they can also be used to represent physical objects.

\subsection{Digital Transformation}

Information technology (IT) is changing our view of products. Products have evolved from being solely composed of mechanical and electrical parts to complex systems of hardware, sensors, data storage, microprocessors, software, and connectivity components. Porter and Heppelmann [1] refer to such new products as smart, connected products. Smart, connected products have opened a new era of competition and business value creation. Three core elements of smart, connected products are (1) physical components, (2) "smart" components, and (3) connectivity components [1]. Several scholars propose to see digitalization as a phenomenon occurring in different "phases" or "waves" over the last decades, the most visible being:

- Digitization: is usually regarded as the first step towards digital transformation. Digitization refers to the fundamental change transforming analogue resources into a digital format [13]. Digitization also imply fragmented automation of isolated operational procedures through the use of digital technologies [1], [13].

- Digitalization: is an intermediate phase in digital transformation. This phase usually acknowledges the concept of being data driven. This means to use and analyze existing data and to utilize this for smarter operations and enhanced products. Enhanced products and services mean that digital technologies are used to provide smarter products with bundled services to enhance the value proposition to customers.

- Digital transformation: In scientific literature, digital transformation often is discussed in the general context of digitalization and considered as the most complex digitalization phase [14]. The focus here is on the disruptive social and economic consequences which, due to the potential of digital technologies to substantially change markets, lead to new technological application potentials and the resulting changes in economic structures, qualification requirements for employees and working life in general [15], [1]. In digital transformation the concept of data driven is fully utilized. This means to capture data in real- 
time throughout the value chain and to continuously utilize this data to adapt and to develop different aspects of the value chain.

More concrete, [16] proposed to distinguish in digital transformation between transformation of the value proposition and the value creation when analyzing and planning digital transformation. These two "dimensions" can be divided into different steps of digitalization which form the prerequisite for the next step, see Figure 1 below.

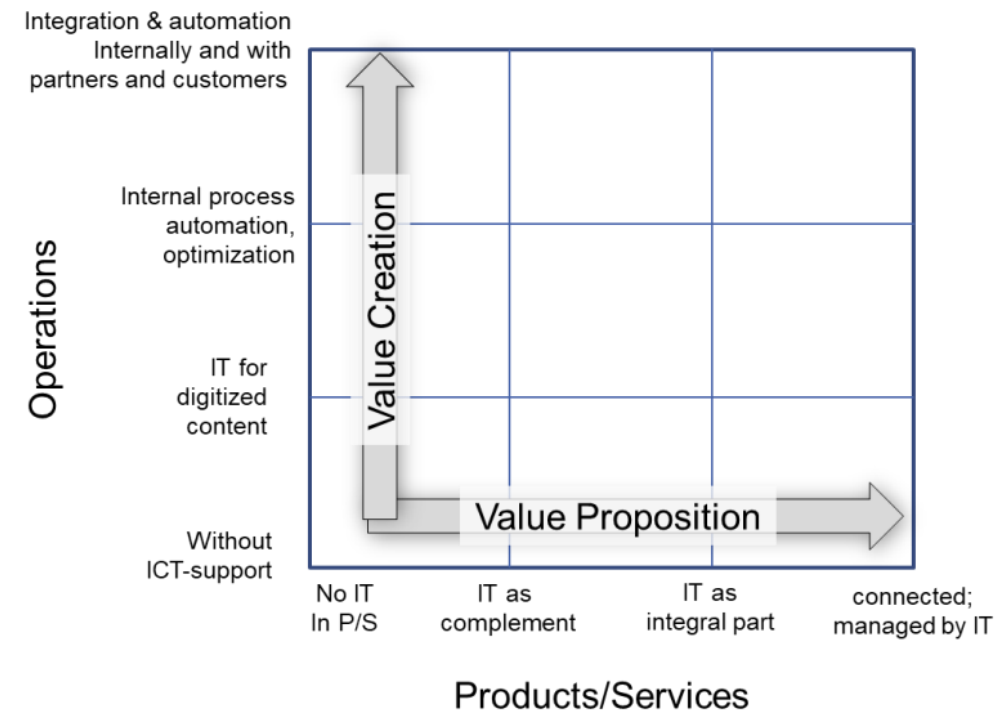

Figure 1. Dimensions of digital transformation and their steps

The main objective with this article is to contribute to a specific support for transformation of products/services and operations by proposing an approach and method components for productIT inclusive EAM.

\section{Research Approach}

The work presented in this article is the result of a research project following the design science research (DSR) paradigm as proposed by [17]. DSR considers that a practical problem can be addressed with the help of an artifact - an object made by humans with the intention to address the problem [18]. Artifacts can be physical objects (a car, a lawn mower), drawings or blueprints, means of methodological support (principles of agile software development, a method for designing a database). The commonality between different types of artifacts is that they aim to support people encountering a problem, which is as an undesirable state of affairs or a gap between the current state and a desirable state [18]. An artifact for solving a problem can be described by the function - what can artifact do for its users; the structure - the components the artifact consists of and how they are related; the environment - the external surroundings and conditions in which the artifact will operate; the effects - how the use of the artifact will change its environment [18].

In this article the problem entails the industrial challenges related to the integration of productIT with enterprise-IT in the context of EA, which had to be identified and described in a structured manner first. Two industrial case studies showed that the architecture of product-IT had similar layers as known from traditional EA for enterprise-IT with substantial commonalities in terms of functionally similar or equivalent services or structures. Thus, integration of productIT and enterprise-IT into a common EA was desirable in order to avoid duplication and competing architectures. However, major challenges were a missing joint management of product-IT and enterprise-IT due to a lack of methodological support and conceptual integration. 
The identified challenges defined the problem space in detail and pointed out the need for the new methodological support in the EA field, which allowed to outline the requirements for the product-IT inclusive EA method. These requirements outlined the function of an artifact that could address the described problem. Afterwards, a suitable structure of the planned artifact was designed, and the method for product-IT inclusive EA was generated. The resulting Method for product-IT inclusive EAM is the central artifact of the study.

Some aspects of the DSR project have been subject of previous publications and will not be repeated in this work. As summarized in Table 1, problem investigation, definition of requirements, and the design and development cycle were covered before. The focus of this article is on core components of the resulting artifact, the method for product-IT inclusive EAM, and the validation of this artifact. To ease the understanding of the method and the motivation for its design and development, Section 4 summarizes the case study and the resulting requirements. Section 5 describes the method components and the validation.

Table 1. DSR phases and their research methods and results

\begin{tabular}{|l|l|l|}
\hline $\begin{array}{l}\text { DSR phase according } \\
\text { to [18] }\end{array}$ & Research Methods applied & Resulting publications \\
\hline Problem investigation & $\begin{array}{l}\text { Literature analysis for investigating the } \\
\text { knowledge base; } \\
\text { Case study for exploring the problem at hand }\end{array}$ & {$[19]$ and [20] } \\
\hline Define requirements & Case study analysis & $\begin{array}{l}{[21]} \\
\text { Summary in Section 4 of this article }\end{array}$ \\
\hline $\begin{array}{l}\text { Design and } \\
\text { development }\end{array}$ & (iterative and incremental development) & $\begin{array}{l}\text { first version: [21] } \\
\text { final version: Section 5 of this article }\end{array}$ \\
\hline Demonstration & Second case study & {$[22]$} \\
\hline Evaluation & Expert interviews & Section 6 of this article \\
\hline Communication & (writing scientific publications) & {$[19],[20],[21],[22]$, and this article } \\
\hline
\end{tabular}

\section{Previous Work}

\subsection{Case Study}

The empirical base for this article is from a research project conducted together with Husqvarna Group AB. This project has served as the main empirical source for the expansion of established EAM to become product-IT inclusive, and as a base to develop an approach and method components to handle product-IT inclusive EAM [22].

Husqvarna Group AB has been and is in the process of transferring their physical products stepwise into smart connected products and at the same time changes and aligns its internal structures, accordingly, especially concerning EA and EAM.

Husqvarna Group AB is a world-leading producer of outdoor power products such as robotic lawn mowers, garden tractors, watering systems, etc. It is multinational and offers products and services for both the private and industrial market. Husqvarna Group AB is heavily engaged in digital transformation where they have embraced many of the opportunities that comes through digitalization.

Many of the Husqvarna Group AB products for professional customers do not only have builtin electronics or embedded systems but also networking and communication capabilities. The built-in IT is in many cases used for controlling the different mechatronic components of the product and for collecting information when the product is in use, either about performance parameters or used product features, or about the environment of the product. The networking features are used for communicating usage statistics, license information or location information (if anti-theft features are activated) to either the product owner or the back-office of the 
manufacturer. Other functions are software upgrades and functionality add-ons implemented by configuration changes (e.g., for optimizing energy consumption).

A typical scenario from a customer perspective is as follows: Different Husqvarna Group AB products are installed for supporting maintenance of the garden, all of them equipped with wireless communication. Among them is (1) a fleet of robotic mowers and (2) a lawn watering system. The robotic mowers and the watering system communicate with each other to synchronize mowing and watering, but they also provide operations data to (3) the base station and receive software updates or operation schedules from it. The base station is connected to the cloud by using the customer buildings WLAN and Internet access. In the cloud, (4) Husqvarna Group AB backend and customer services are available. Thus, the owner of the garden has access to the services for operating, supervising and planning the garden maintenance using (5) mobile devices.

As an initial step, Husqvarna Group $\mathrm{AB}$ had to create alignment between different product lines in terms of interfaces, communication standards, and functionality, i.e., regarding networking, communication and service provision. In this, Husqvarna Group AB designed and implemented reusable services and components (Common Services) for both the product lines and the back-office infrastructure which provided an IT and service architecture for the product lines.

An example of a challenge during this phase was the software license management for products and software licenses for traditional enterprise-IT (accounting, finance HR, etc.). Husqvarna Group AB had to secure a technical infrastructure and use the same encryption and logging services for product software and enterprise software. This was done through defining common enterprise architecture elements for both product-IT and enterprise-IT. During the development of the common enterprise architecture Husqvarna Group AB had to address and handle a number of dimensions of the enterprise (concepts and constructs) that are not included in traditional EAM.

In the second phase, somewhat in parallel with phase one, Husqvarna Group AB addressed its work procedures (operations) in order to handle the bimodal lifecycle (Mode 1 and Mode 2) of product-IT and enterprise-IT. A bimodal lifecycle is a direct consequence of addressing enterprise-IT and product-IT in an integrated way. Enterprise-IT (Mode1) is designed for stability, efficiency, and low cost, which is closely related to traditional enterprise architecture management (EAM). Product-IT, on the other hand, (Mode 2) is constituted by development projects that help to innovate or differentiate the business. This requires a high degree of business involvement, fast turnaround, and frequent updates, the so-called rapid path to transform business ideas into applications. To handle Mode 1 and Mode 2, Husqvarna Group AB has implemented DevOps Teams designed for agility, rapid development and short time to market.

\subsection{Requirements for a Product-IT Inclusive Method Support}

Based on the observed and described challenges in the case study above, it was possible to formulate requirements (REQ) for the envisioned artifact, the method for product-IT inclusive EAM (see also [21]).

REQ 1: The method should support that product-IT is a part of strategy development, operational development, and technology development.

The market changing potential of digital technologies often leads to substantial changes of entire business models [2]. Also, a competitive advantage often requires the implementation of operational effectiveness (OE) [16]. OE requires embracing best practices across the value chain, including up to date product technologies, the latest production equipment, and state-of-the-art sales IT solutions. The boundaries between IT supporting business functioning, digital services that increase the value of the products and automation of manufacturing become fuzzy, as they all act as parts of the digital assets of an enterprise and need to be considered in a structured and 
coherent manner both in terms of strategical and operational choices. This motivates the importance of formulating a digital strategy that would allow not only achievement of OE, but to create positioning that would allow strategic differentiation [16]. The practice of EAM has a broad range of frameworks and tools for translating strategy into implementation and can therefore be used for developing and implementing digital strategies, where product-IT will be considered as a crucial part.

REQ 2: The method should be applicable in the environment where agile mode of IT development and traditional waterfall-like mode of IT development co-exist.

A challenge that is apparent today in the digital transformation is the ability to handle the bimodal dimensions of the IT development. The enterprise-IT dimension (Mode 1), is designed for stability, efficiency, and low cost, and is closely related to traditional EAM while product-IT (Mode 2) is constituted by development projects that help to innovate or differentiate the business and require a high degree of business involvement, fast turnaround, and frequent update, the so-called rapid path to transform business ideas into applications.

[23] stated that there is a need to handle "A two speed architecture for the digital enterprise". For digitally native enterprises and startups this is not a problem, since they have had the benefit of starting with a "clean slate" and think "digital" and take the advantage of this from the beginning without considering any legacy. This does, however, not work for more established enterprises. They have many years of delivered technology, architectures, governance, decisions structures and financing mechanisms. The central objective of the approach in this article is to differentiate the systems, architectures, and structures that must be flexible and agile (often on product-IT side) from those that have to be more reliable and deliver the highest quality (often on enterprise-IT side) [23].

REQ 3: The method should provide means for many-sided analysis and modeling of EA, paying substantial attention to the role of product-IT in business value generation and strategy development.

On one hand, many-sided analysis and modeling implies the set of clearly defined EA layers. A new EA method has to enable collaborative support for knowledge representation across different layers and domains and navigating through them easily.

This need to cut through several layers and navigate through them is related to the concept of multi-level dynamic that is also discussed by [23]. The authors of [23] argue that the enterprise architect would need to understand the differentiating attributes of different levels and place enterprise activities within each level. The constituent activities of any process could be moved across level boundaries however the resulting implications of this would need to be traced. In that study several enterprise representatives have emphasized the need to pay significant attention to strategy formulation and implementation that would involve product-IT concerns.

On the other hand, to enable many-sided analysis and modeling of product-IT inclusive EA, a set of illustrative constructs relevant for the context has to be identified - a set of focal areas, each including one or several related elements, that allow to illustrate the most important issues in the context.

One important focal area in this context is customer journey. The customer journey model describes the set of steps of a customer (or end user) together with different touchpoints that characterize his/her interaction with the service or a product. The model can include the following elements: actor; products and services offered to an actor (offering); phases of the journey (processes or steps); concerns; thoughts and emotions (experiences); touchpoints.

Data-driven business options also require consideration in the product-IT inclusive EA. Datadriven business options are a focal area that allows to represent the connection of people, their concerns, the entities producing data, and the value of the data in relation to the people's concerns.

These two focal areas (customer journey and business options) are important to analyze product-IT contribution into business value generation. However, they are not coherently supported by the existing methodological support for EA modeling. 
REQ 4: The method should address data as one of the resources for value generation.

The importance to develop products and services in a data-intensive way becomes obvious for many companies, as data plays the role of the key asset that companies own or have access to. Business models are being reshaped, products and services are being enhanced, the ways to generate and deliver the value to the customers are being changed through data exploitation. Data-driven sensing and acting described in [23] suggests that enterprise change is being influenced by both the internal adoption of technologies and the general pervasiveness of digital technologies in the environment that they operate in. This kind of data-driven sense- and response loops for ongoing enterprise transformation already exist in multiple industries and often are realized by the mechanisms of Big Data analysis.

The analysis of the data, focusing on the app feature usage, helps to optimize the features and facilitate further product improvement, which in the long run increases the value of the product for the customer and can address broader range of the customer concerns. Continuous analysis of data from usage situations for products and services, throughout the development, operations, and maintenance, helps to enhance the customer experience.

REQ 5: The method should facilitate stakeholders' collaboration and interaction.

There is a need to facilitate the collaboration between various groups of stakeholders with different organizational belonging. The need for representational, collaboration and interaction mechanisms that can be used to support a dialog between stakeholders with various backgrounds (squad leaders, product owners, marketing specialists, graphical designers and others) becomes apparent and crucial to address. For instance, [16] points out the need for close collaboration between IT and Research \& Development and continuous customer success management.

According to [23] the particular issue for an enterprise architect is the need to be able to depict actor autonomy, actor objectives and goals, boundaries of actor influence, multiple levels at which these objectives and influences span, and interactions between the actors. Also, it will be important to show any alignment (or misalignment) of actor objectives with the enterprise-level objectives.

\section{Approach for Product-IT Inclusive EA}

This section presents the approach for product-IT inclusive EAM with its different methodical and conceptual components. One of the basic principles when developing the approach was to build upon established industrial practices whenever possible, i.e., to design method components and supporting tools that can be integrated into established EAM structures and processes in enterprises instead of replacing them. This principle basically emerged both as a requirement from the industrial case motivating this work (see Section 4.1 and [22]) and the analysis of the state of the art in EAM which showed the feasibility of such an integrative approach.

TOGAF and ArchiMate (see Section 2.1) are among the most widely used EAM approaches in industry, and they form an environment suitable for integrating our approach to product-IT inclusive EA. The core element of our approach is the focal areas during business architecture development, i.e., when transforming towards smart connected products and integrating productIT into business models and EA, enterprise should pay specific attention to the focal areas and apply method components from our approach in doing so. The focal areas are:

- Customer journey. The journey model describes the set of steps of a customer (or end user) together with different touchpoints that characterize his/her interaction with the service or a product.

- Data-driven business options focal area allows to represent the connection of customer groups, their concerns, the entities producing data and the value of the data in relation to the customer group's concerns.

- Business ecosystem concerns the product and services (offerings) within the company under consideration and what company-internal ecosystem they form. This helps to identify and 
represent the key actors and their relationships within an ecosystem. An ecosystem is defined by an offering or groups of offerings.

- The interaction focal area allows to represent relationships and communication (exchange of interaction objects) between stakeholders.

- The technological support of offerings is a focal area that allows to represent the relevant and potentially useful technology areas that enable successful functioning and development of an ecosystem of offerings.

- The innovation agenda focal area aims to represent relevant technology areas, both currently used and potentially applicable, in the value creating activities of the company. Representation and analysis of innovation agenda can be used to prioritize the technology areas within a digital transformation effort. This focal area also allows to represent business actors who are assigned to the identified technology areas, and link product-IT and enterprise-IT with the identified technology areas.

The results of working in the focal areas during business architecture development will have implications for the application architecture. This is most obvious for the data-driven business service area which has to be implemented by creating or adapting IT-services, applications or interfaces in the application architecture. Figure 2 illustrates the positioning of the focal areas and their corresponding method components in TOGAF ADM.

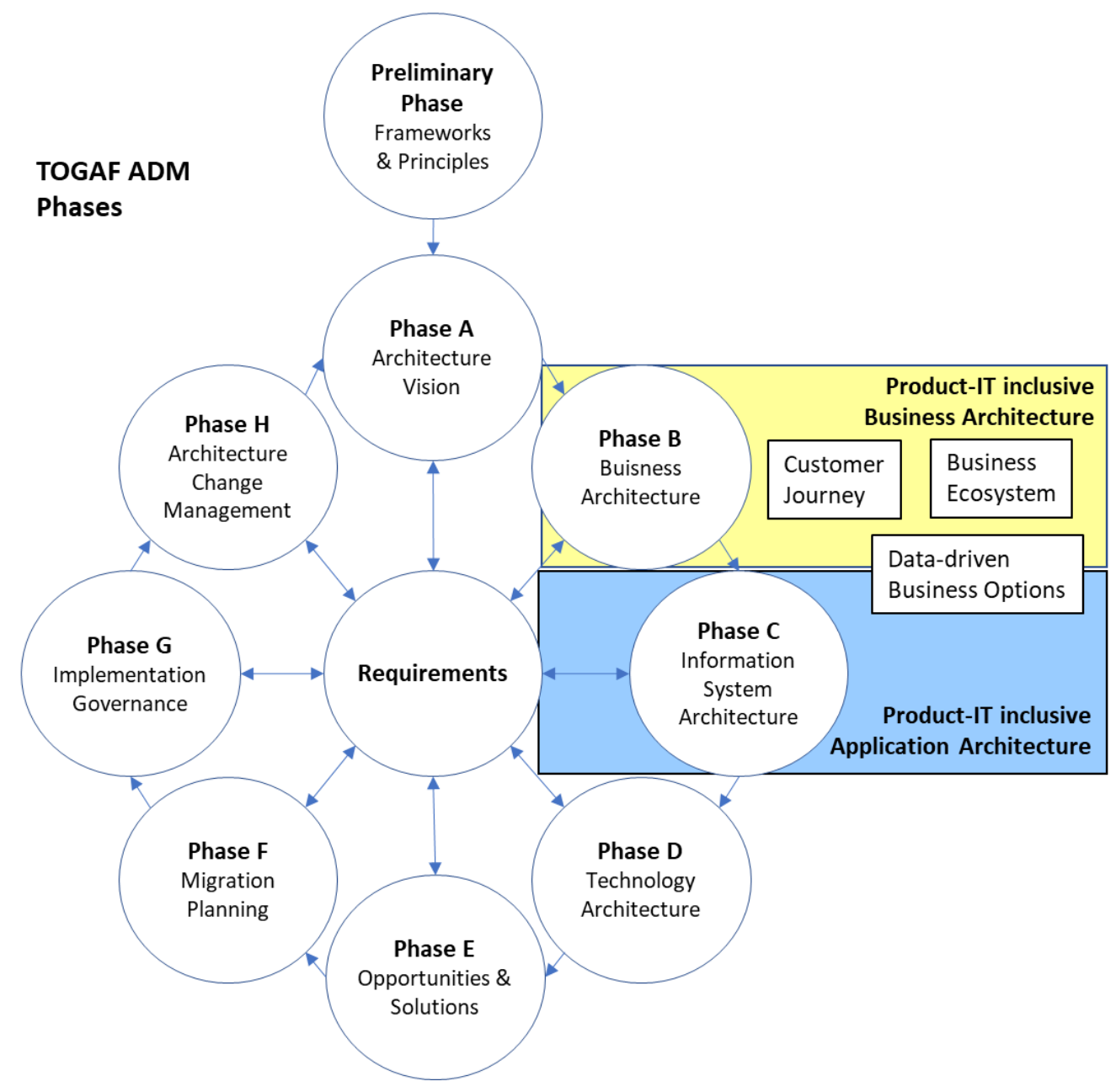

Figure 2. Focal areas and their relation to TOGAF ADM

How to actually proceed for the different focal areas is defined in a separate method component for each focal area. All method components share the same concepts and involve defined stakeholders. This integration of components and the overall definition of components follow principles from method engineering that will be presented in Section 5.1. In the context of 
this article, the focal areas business ecosystem, customer journey and data-driven business services were selected for presentation, which follows in Section 5.3.

An important aspect of method engineering and at the same time an element of the integration into TOGAF and ArchiMate is the definition of the concepts that are used by the method components and their integration into EA modeling languages, such as TOGAF. From a technical perspective, these concepts were described as a meta-model for product-IT inclusive EAM, which is an extension of ArchiMate and is presented in Section 5.2.

\subsection{Method Engineering Perspective}

The resulting method was structured as a combination of several constituents, which are interconnected and linked to each other. The choice of the constituents was based on the method requirements and their implications on Goldkuhl et al.'s method theory [24]. The relationships between constituents are presented in Figure 3 and described below.

According to [24] a method should include defined method perspective - what is considered important in the method. The method perspective for the resulting method is represented by the formulated requirements for product-IT inclusive EA method.

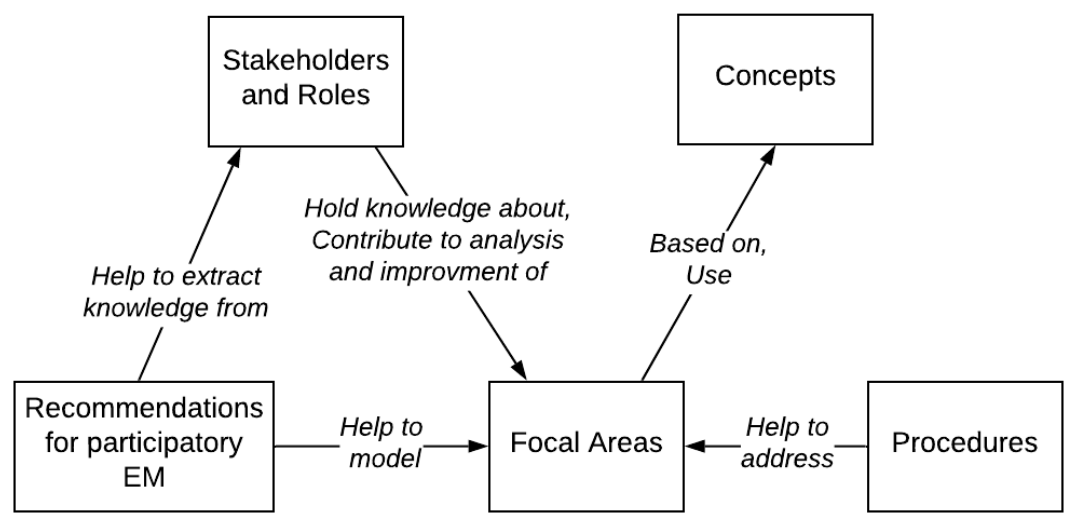

Figure 3. Resulting method - the constituents

Concepts are the essential entities within a domain. In this article, presented concepts are the key entities in the product-IT inclusive EA and provide the essential ground for all other constituents of the developed method. Concepts are providing the terminology in which the domain knowledge can be discussed and modeled. Concepts are fundamental to the introduced method and are used as a basis for focal areas and procedures. From the point of view of method theory, concepts for product-IT inclusive EA correspond to the full set of concepts relevant for the context that the method aims to address. This full set of concepts define conceptual basis of the method and helps to answer the question What to talk about? for the defined focal areas. Concepts for product-IT inclusive EA are presented in Section 5.2.

Focal areas are relevant illustrative constructs for representing a domain. The focal areas for product-IT inclusive EA are enabling representation of the product-IT as a part of EA, showing the relationships between product-IT parts and other EA elements. Each focal area is defined by a set of interconnected concepts. The resulting method includes several focal areas specific for representing product-IT inclusive EA. From the point of view of method development theory, a focal area can be compared to a method component defined by [24]. According to [24], to form a method several method components can be defined, where each method component includes concepts, procedure and notation. In this article, focal areas include concepts and procedures, whereas the notation, i.e., how a concept should look like to enable graphical method usage (How to express answers?), is left outside of the research scope.

Procedures can help to model the defined focal areas. Procedures are stepwise guidelines for modeling the focal area for the purpose of further analysis. Procedures are addressing the 
concepts of the focal areas, by which the focal areas are defined. Focal areas and corresponding procedures are presented in Section 5.3.

Stakeholders and roles are stakeholders and roles (a responsibility assigned to an actor) that should participate in the modeling activities of the focal areas. On one hand, there are stakeholders that possess the domain knowledge of the focal areas within product-IT inclusive EA and can contribute in knowledge representation in participatory settings. A set of stakeholders and roles is specific for each focal area, which provides guidelines on Who answers questions? On the other hand, there is a modeling facilitator - Who asks questions? Combined, these two groups (Who asks questions? and Who answer questions?) correspond to Co-operation and collection principles from the method development theory [24].

\subsection{Meta-Model for Product-IT Inclusive EA}

The previous section described the importance of identifying the relevant concepts when specifying a method or method components. The concepts of the method for product-IT inclusive EA can be expressed in a meta-model. This meta-model builds upon the meta-model of ArchiMate and extends it by concepts specific to product-IT as an addition to EA. These concepts are motivated by the method requirements (see Section 4.2) and used by the method components (see Section 5.3).

Figure 4 illustrates the meta-model by presenting an extended concept model with rounded rectangles representing concepts and connecting lines relationships. White rectangles indicate that the concepts are present in ArchiMate and blue rectangles are the extensions made for product-IT. These extensions are:

- Offering: Offering should be introduced as a new concept to combine products and services in one phenomenon that has a purpose of value creation. Offering is capable to provide a value to a person via solving his/her problem or concern.

- Ecosystem: An Offering together with key actors constitutes an ecosystem. Business ecosystem is an idea that is changing strategic, business and operating models and gets more and more recognition in companies across the globe. Ecosystem can be defined as a complex web of interdependent enterprises and relationships aimed at creating and allocating business value [25]. Companies can drive greater value from ecosystems by increasing the strategic impact of ecosystem engagement to their businesses, improving access and lower cost of skills and expanding the scope of strategic business opportunities and initiatives.

- Touchpoint: Touchpoint is an important concept for defining interactions. Customers develop experiences every time they interact with a product, service or the enterprise as a whole, across multiple channels and at various points in time [26]. Such options of interaction between the customer and any part of the enterprise are known as touch points [27]. Both existing and potential customers can interact with the company via touchpoints, which means touchpoints can be divided into pre-purchase, purchase and post-purchase, and interactions can happen via various channels such as person-to-person, website, an app or any form of communication.

- Experience: The idea of experience has been widely discussed in the field of marketing as the internal and subjective response customers have to any interaction with a company [28]. The subjective nature of the experience is elucidated by [15] which indicate that experiences are inherently personal, existing only in the mind of an individual who has been engaged on an emotional, physical or intellectual level. Experience is a subjective reaction of an actor, and it can influence the value of the consumed offering.

- Concern: Concern is closely related to Value and Experience. Value is defined as a motivation element in ArchiMate. Value represents the relative worth, utility or importance of a core element or an outcome. Though value can hold internally for some system or organizational unit, it is mostly applied to external appreciation of goods, services, 
information, knowledge, or money, normally as part of some sort of customer-provider relationship. However, in the discussed context, the value of an offering cannot be considered separately from the experience that an actor perceives when consuming an offering. In addition, to propose a relevant offering, it is crucial to know the concern that an actor has. This motivates the need to introduce the concept "concern".

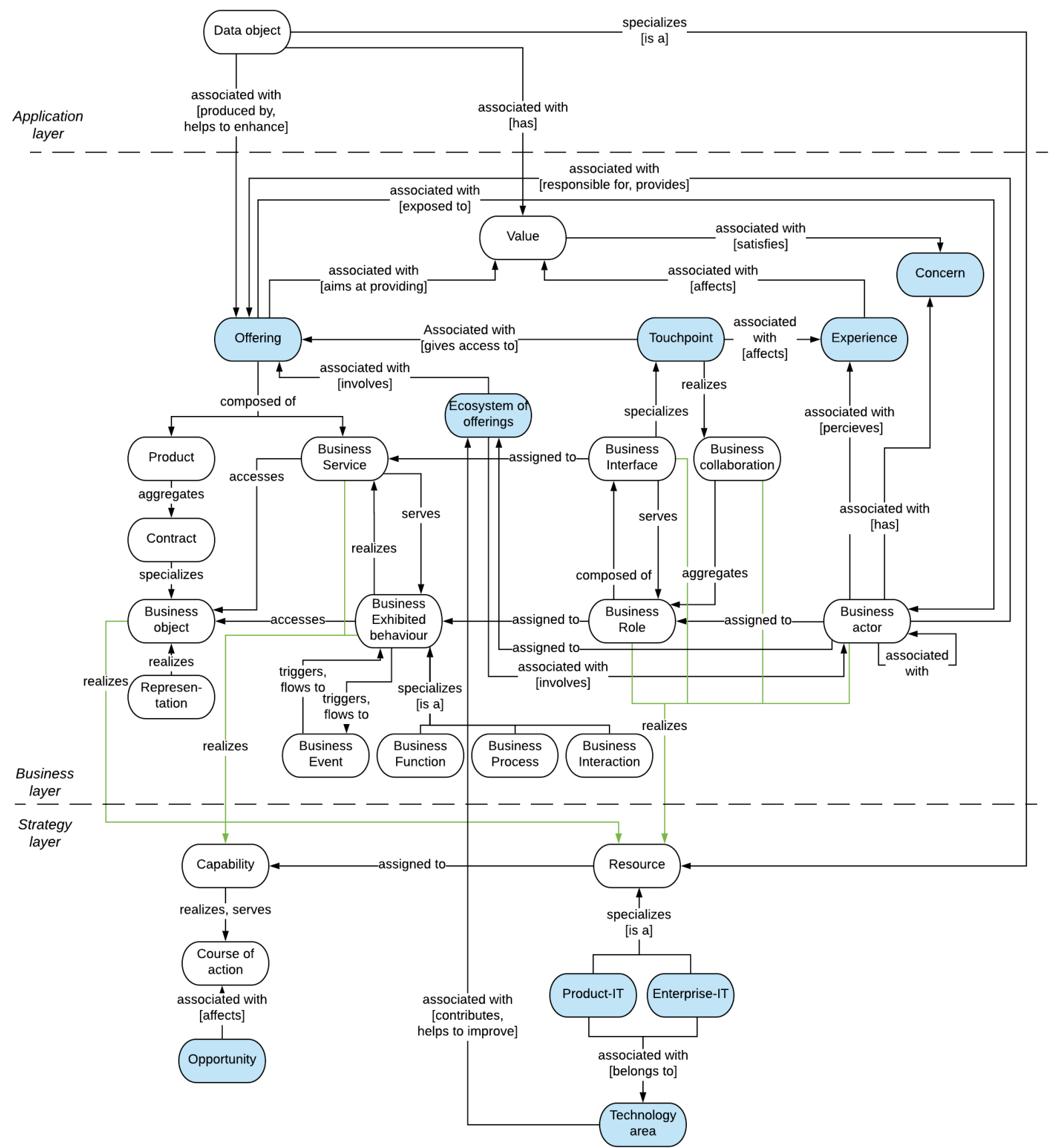

Figure 4. Extended concept model for product-IT inclusive EA based on ArchiMate concepts

- Opportunity: Opportunity is a possible way to develop an enterprise of technical or business character. Opportunities differ from capabilities - existing enterprise assets of various sorts, for instance, skills of an employee, specific kind of production equipment, etc. Opportunities and capabilities are supporting digital strategy, but at the same time drive and influence it. Opportunity is somewhat similar to the Driver motivation element defined by ArchiMate. However, a driver has more general character and the connection between driver and the strategy layer is not defined. 
- Technology Area: Technology area is a concept that represents a domain, which aims at solving a certain challenge and includes a range of IT-intensive methods and solutions to solve this challenge. Examples of technology areas are Artificial Intelligence, Voice Recognition, API Management, Identity Management, etc. One technology area can include numerous enterprise-IT and product-IT application and technology components.

For some of the extensions, there are concepts in ArchiMate that could have been used to represent them, e.g., ArchiMate's "business collaboration" to model "ecosystem" or ArchiMate's "driver" to model "concern". However, the semantics of Ecosystem and Concern is slightly different from Business collaboration and Driver, which supported the decision in favor of the extensions.

\subsection{Selected Method Components}

Based on the concept model in previous section we have selected three method components for further presentation, namely, ecosystem of offerings, customer journey and data-driven business options. The main reason for the selection of these three method components is that they are the method components that cater for bridging the gap between product-IT and enterprise-IT and to make EAM product-IT inclusive. The presentation of the method components follows the same structure for each method component: we start with the concepts from the meta-model (see Section 5.2) of particular importance to the method components, which is followed by a brief description of the objective of the method component. Subsequently, an example from the case study presented in Section 4.1 is given and the procedure to follow within the method component is summarized.

\subsubsection{Ecosystem of Offerings}

Concepts incorporated: Business ecosystem is a focal area that incorporates business actors, ecosystems of offerings, concerns and offerings (Figure 5).

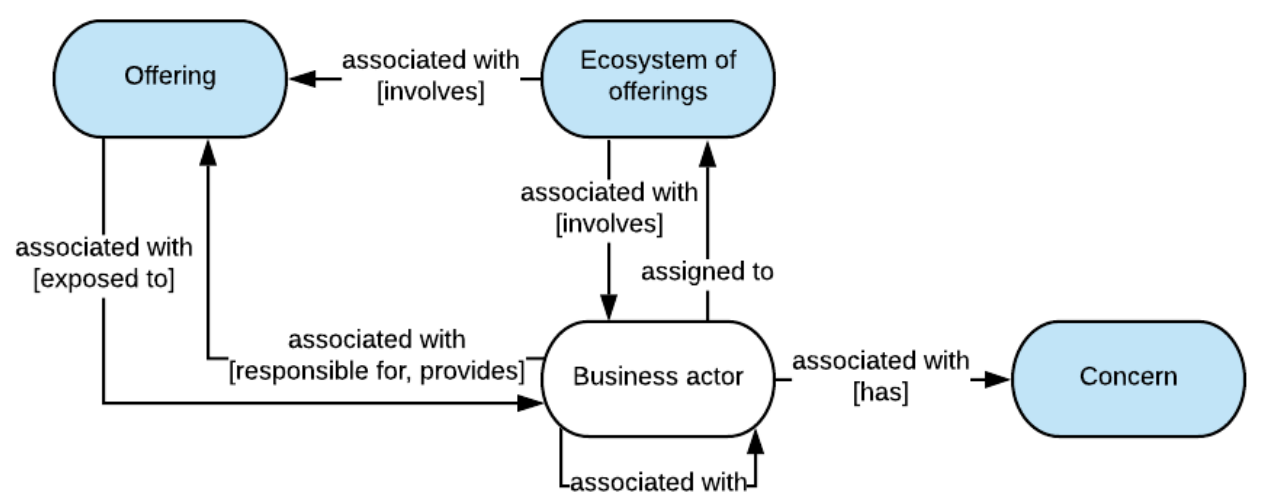

Figure 5. Ecosystem of offerings - included concepts

Objective: This focal area helps to identify and represent the key actors and their relationships within an ecosystem. An ecosystem is defined by an offering or a group of offerings. Various offerings can be logically grouped into several ecosystems depending on the nature of the concerns that these offerings can to solve. Offerings can be tangible and intangible, for instance, products, services, information; and can partly or fully solve actors' concerns.

Ecosystem of offerings helps to show the overview of the important internal and external actors and their relationships; analyze existing and develop new business models based on the offerings and concerns; and identify existing and potentially relevant actors based on the offerings and concerns. 


\section{Illustrative example from the Case Study}

Ecosystem of offerings focal area aims to provide an understanding of products and services (offerings) that belong to the given ecosystem and its key business actors. Four ecosystems of the case company are represented in Figure 6 together with the offerings that each of the ecosystems involves and business actors, in this case internal organizational units, who are assigned to each of the ecosystems.
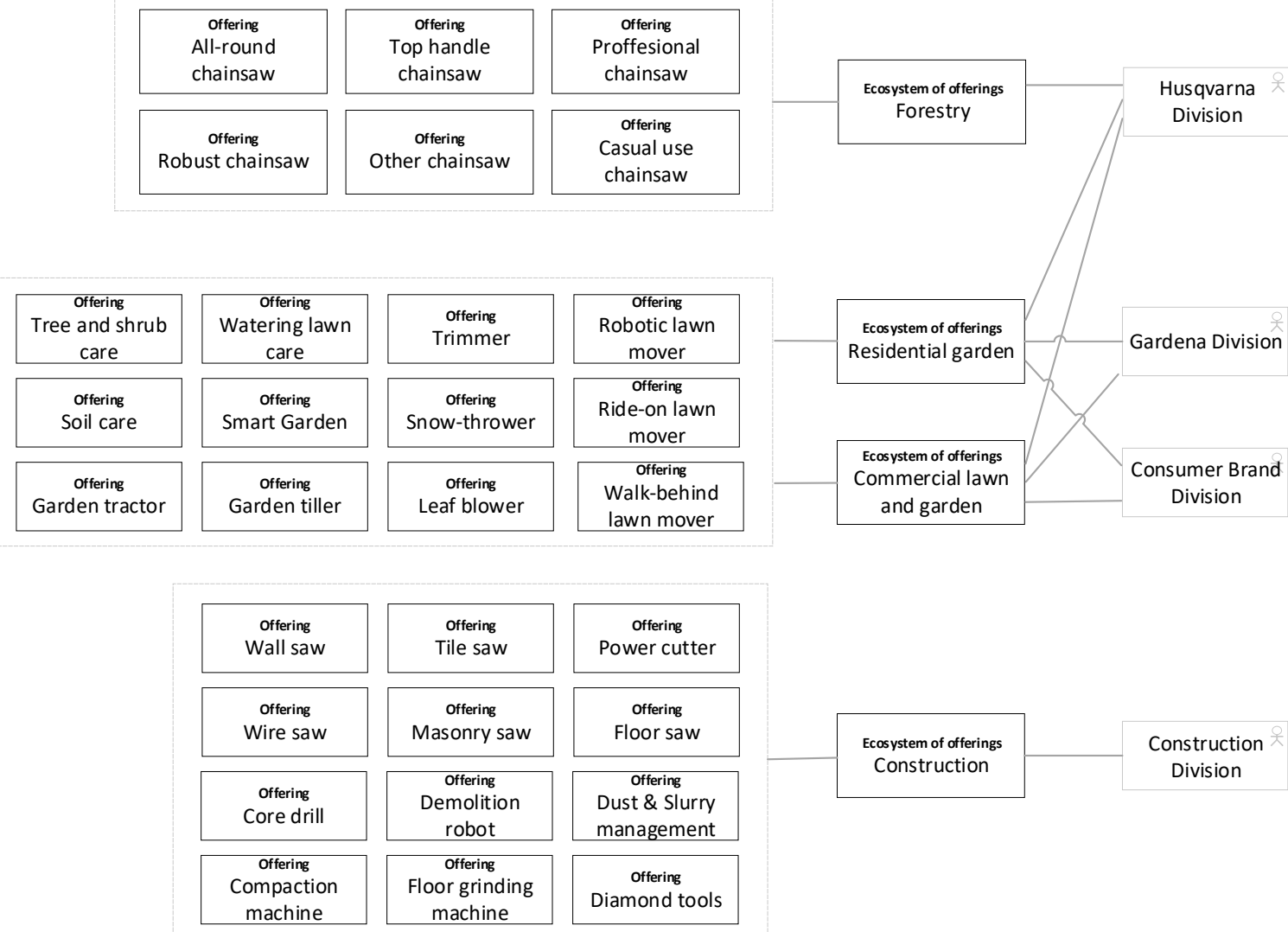

Figure 6. Ecosystems of offerings, the key offerings and involved actors

The model in Figure 7 represents the key competitors (represented as business actors) in the Forestry ecosystem, shown in Figure 6, focusing on a chainsaw as an offering.

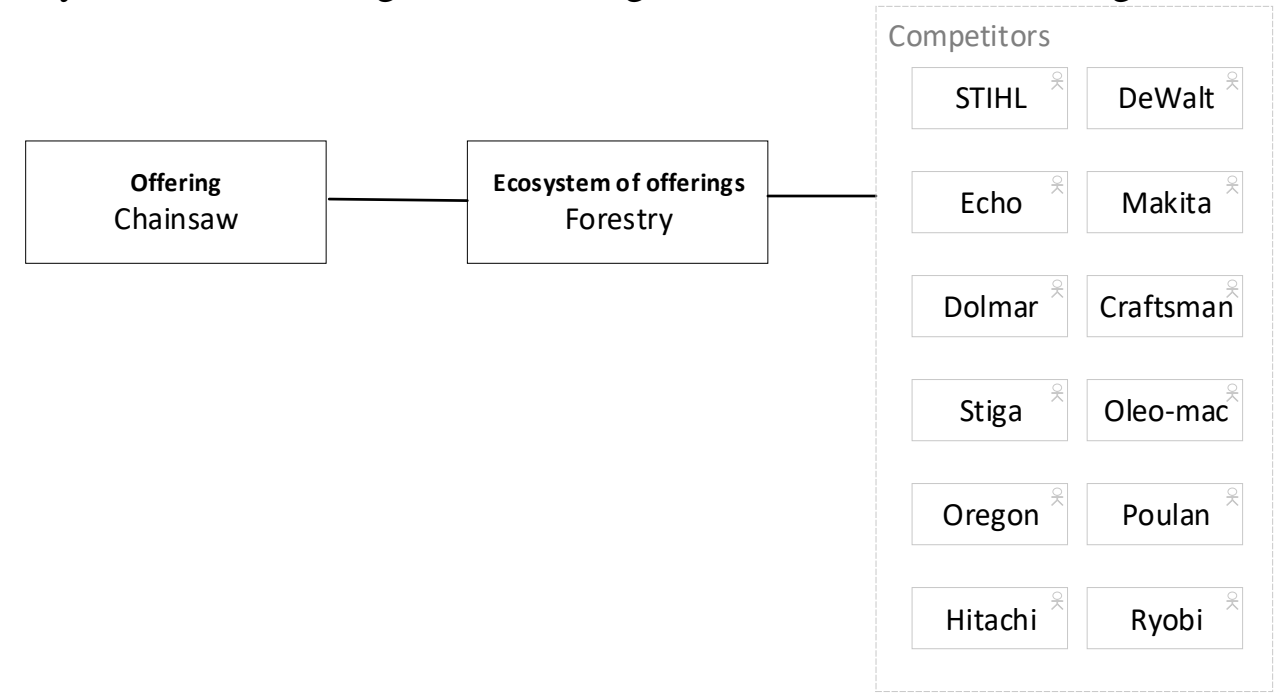

Figure 7. Key competitors in the Forestry ecosystem of offerings, chainsaw offering 
Another important aim of ecosystem modeling is to analyze the high-level concerns that the stakeholders have - below in Figure 8 an example of customer concerns model in Residential garden ecosystem of Figure 6 is presented. Providing an overview of high-level concerns helps to keep the focus on the real needs and requirements of stakeholders (e.g., customer groups) and therefore allows to go beyond providing products in a traditional sense and to combine products and services or substitute products with services completely.

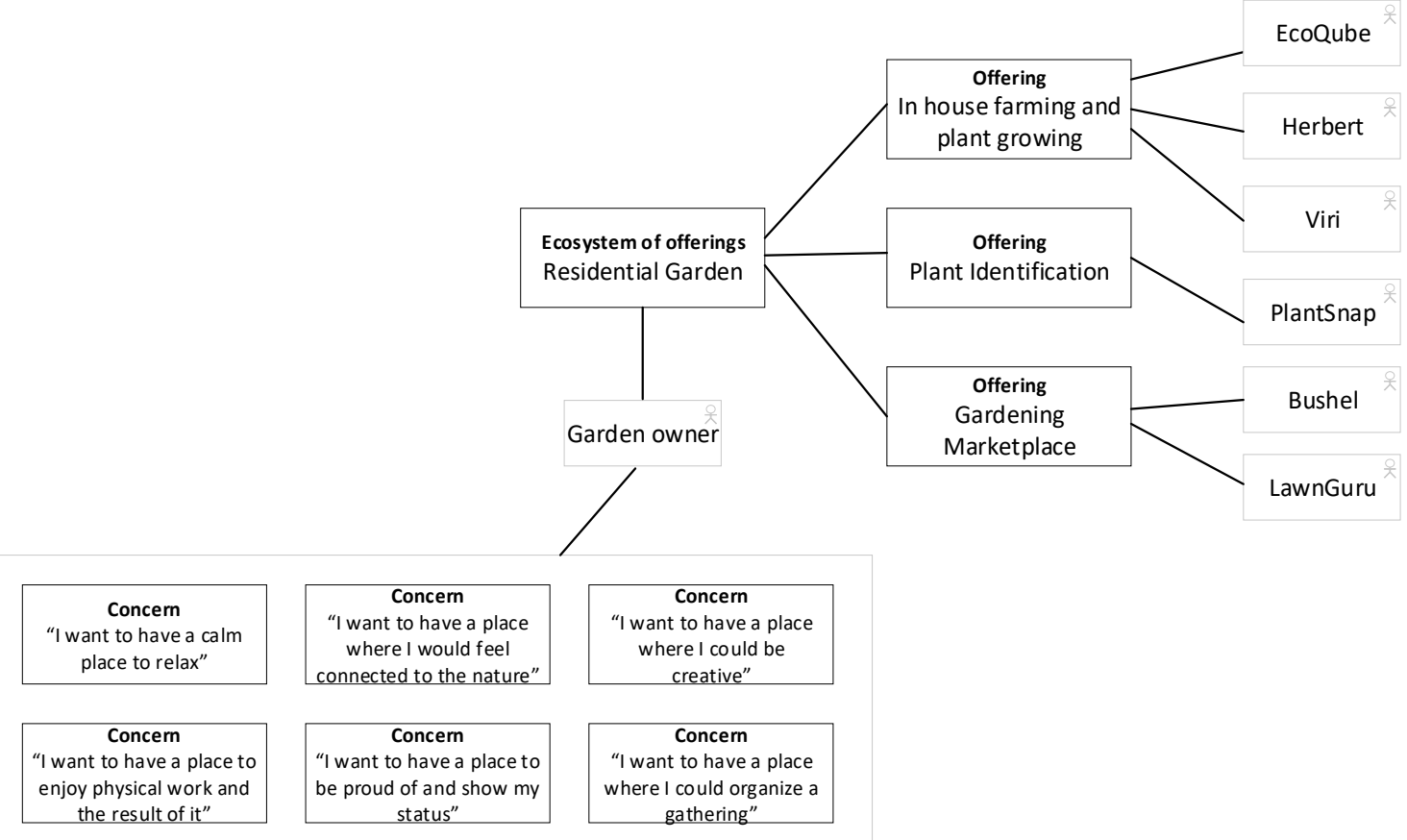

Figure 8. Residential garden ecosystem, offerings with the related actors and key concerns that are relevant for the garden owner (business actor)

Procedures: The procedure for modeling of ecosystem of offerings includes five steps and is based on the concepts that define this focal area (Figure 9).

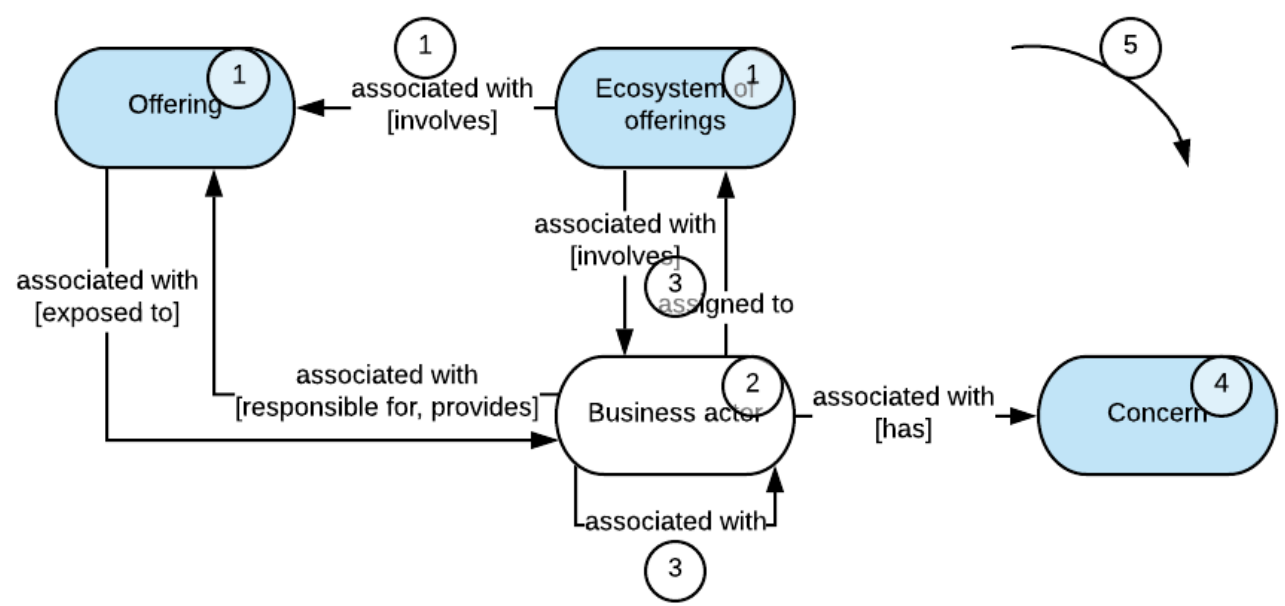

Figure 9. Procedures for modeling of ecosystem of offerings

1. Set the scope for analysis and identify the offerings that are important within the chosen scope. The offerings can be tangible or intangible, e.g., services, products or other value adding things. After the offerings are identified, group them. Each of the created groups correspond to an ecosystem of offerings. Set a suitable name for each ecosystem based on the character of the included offerings. 
2. Identify the important actors. They can include stakeholders that contribute into providing the key offerings or play other important roles in the given ecosystem. For instance, you can consider competitors, trend setting players on the market, providers of the competence or technological solutions, providers of the relevant information or data, customer groups, potential partners. Actors can be individuals, groups of people or other communicating entities.

3. Represent the actors and their relationships. For this, analyze collaborative, competitive and other types of relationships between the identified actors.

4. Consider and identify the concerns that the actors have. For this, analyze incentives and pain points (general or detailed) of the identified actors. List the concerns and relate them to the identified ecosystems. Analyze which concerns can be resolved with the help of the existing offerings from the identified ecosystems, and which ones remain unresolved and can provide basis for new offerings and ecosystems.

5. Review and refine.

\subsubsection{Customer Journey}

Concepts incorporated: Customer journey focal area incorporates business actors, business processes, concerns, offerings, experience and touchpoints (Figure 10).

Objective: Customer journey aims to represent a sequence of steps and touchpoints that a business actor goes through in relation to an offering or group of offerings and focus on the concerns and experiences perceived by the business actor.

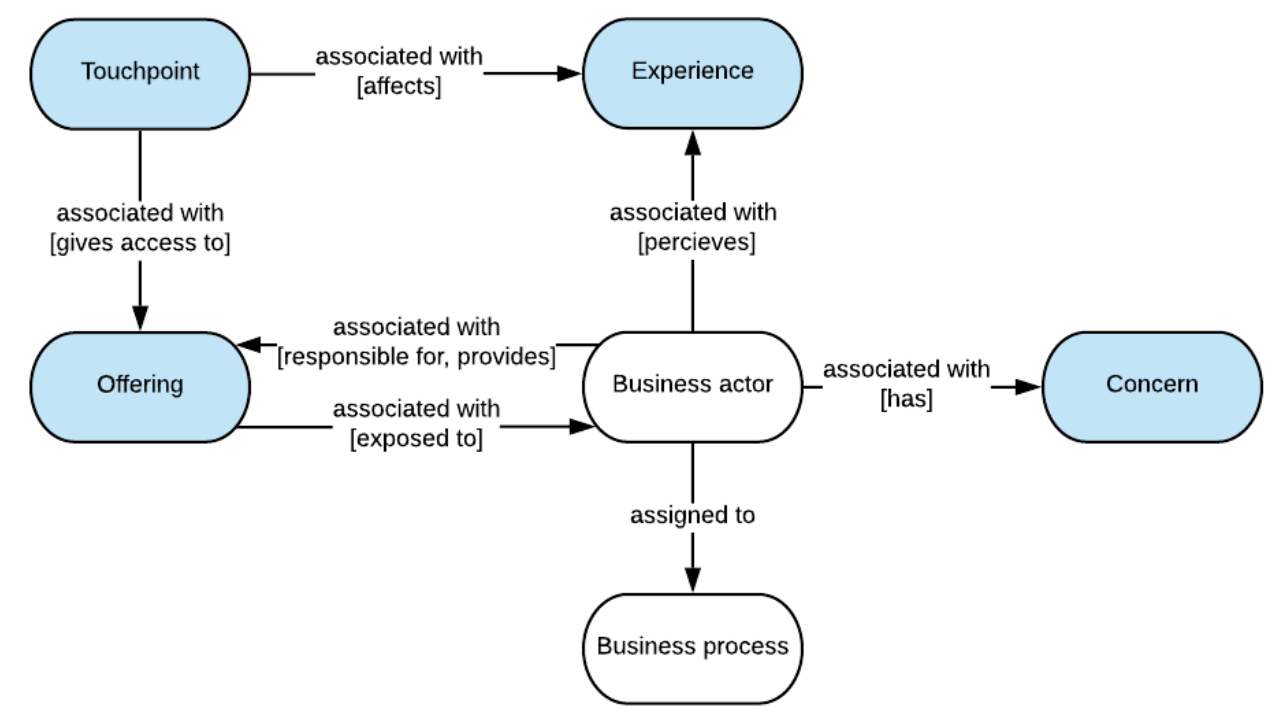

Figure 10. Customer journey focal with included concepts

\section{Illustrative Example from the Case Study}

An example of customer journey model is presented in Figure 11. This model shows eight steps (business processes) of customer journey related to the usage Lawn Mower Connect mobile app in the context of the ownership of the smart, connected lawn mower. A number of customer concerns (why does the person open the app) were identified and assigned to the steps of the journey.

Afterwards it was possible to prioritize one of the concerns (marked with green dot in Figure 11) for further analysis. More detailed analysis of the customer's concerns was performed and possible touchpoints (in this case In-App messages) were identified. The aim of the proposed touchpoints was to solve customer's concern by referring to the existing offerings. For the proposed touchpoints the customer experience was analyzed and the priority for implementation was set on the In-App message "Did you hear about winter storage as a service?" (marked with green dot in Figure 12). 


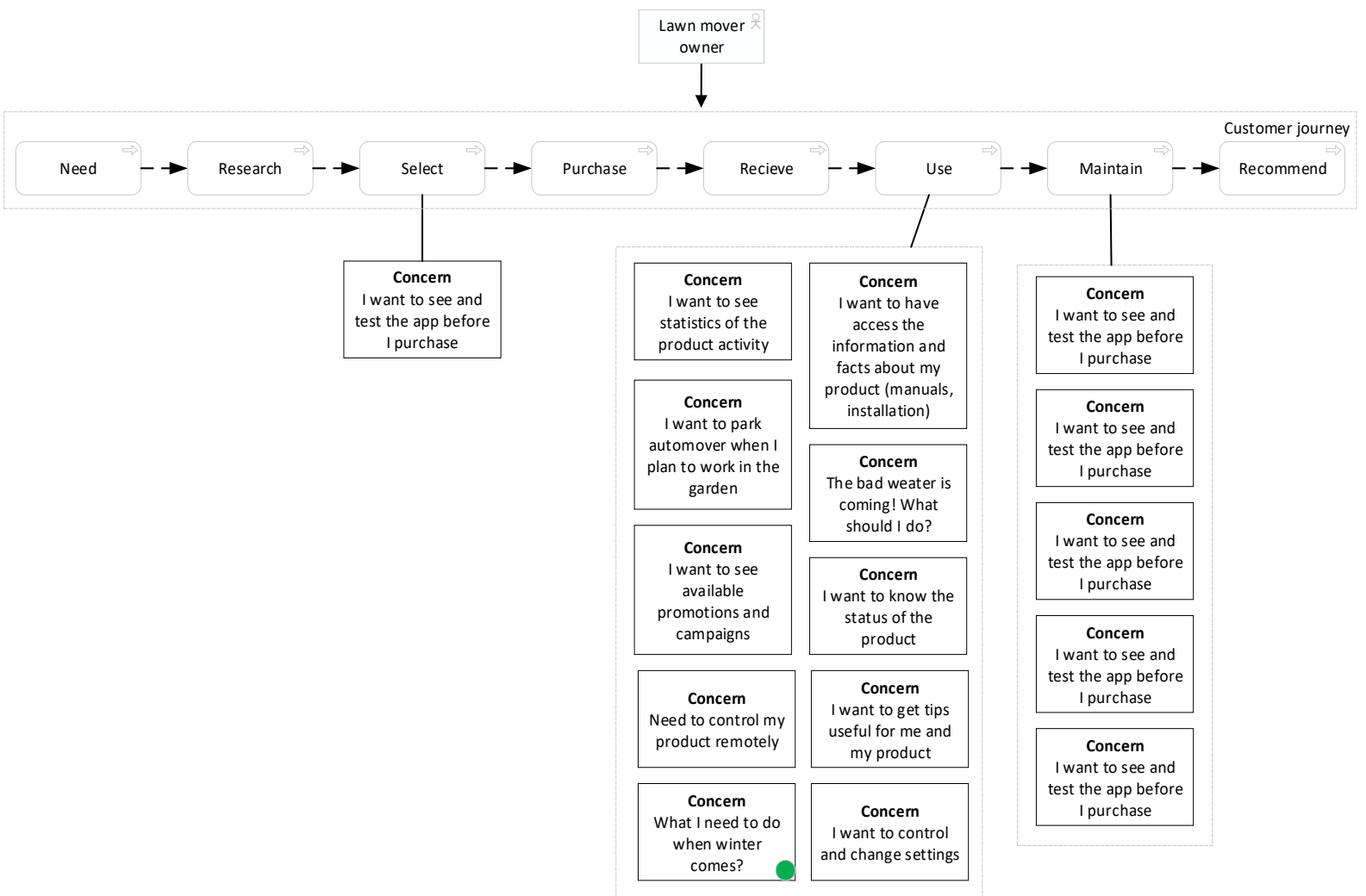

Figure 11. The customer journey and related customer concerns in the context of Lawn Mower Connect mobile app usage

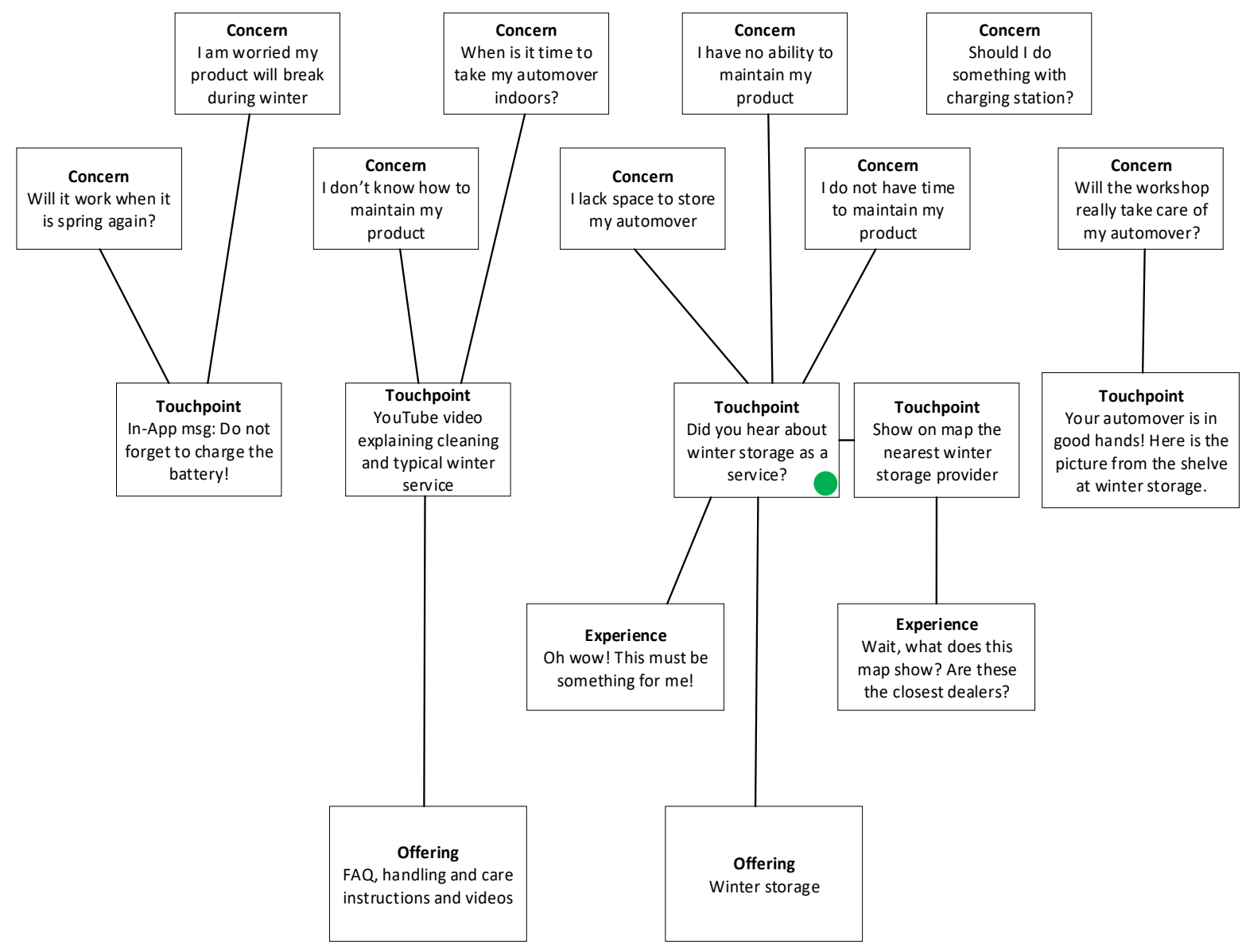

Figure 12. Customer concerns, touchpoints and offerings 
Procedures: The procedure for modeling of customer journey includes seven steps and is based on the concepts that define this focal area (Figure 13).

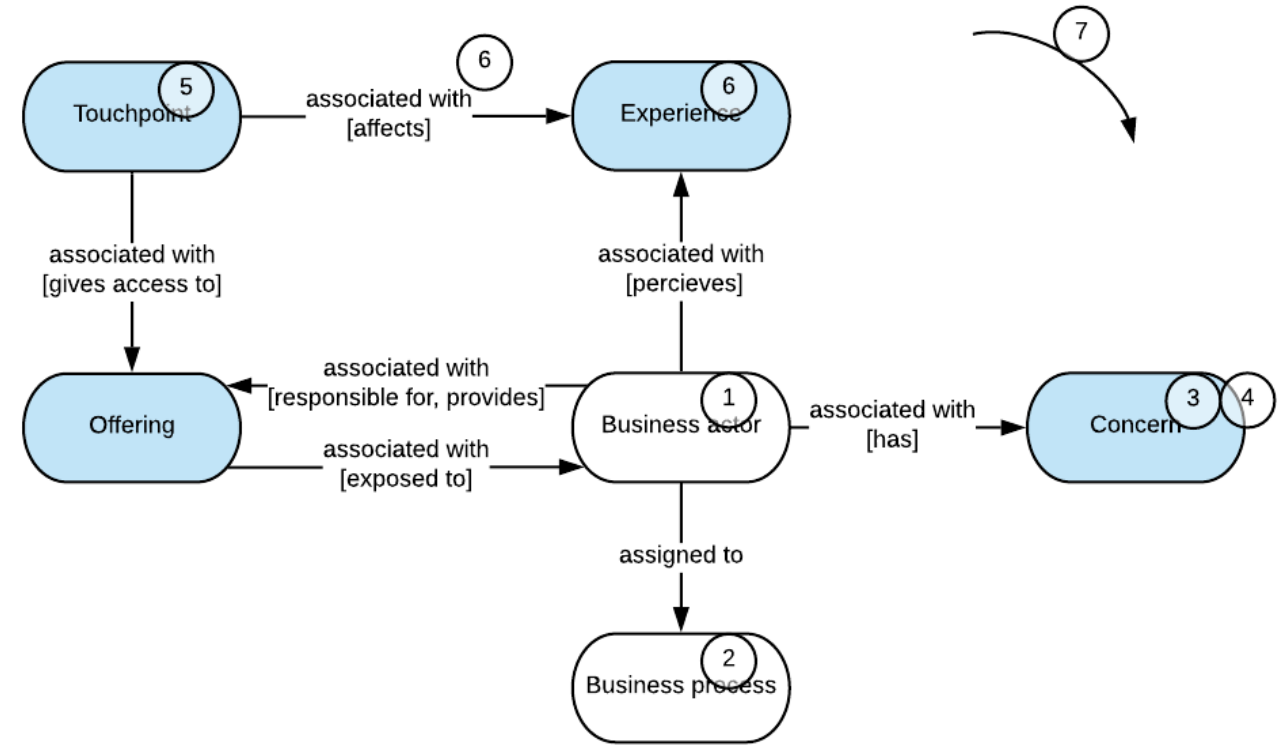

Figure 13. Procedures for modeling of customer journey

1. Set the scope for analysis and identify the business actors that you would like to focus on and the offerings relevant for the context. The focus can be set on an individual or a group of actors, who can be internal and external, potential and existing consumers of the value creating offerings.

2. Represent the key steps of the customer journey for the identified scope - a sequence of business processes. One way to structure the journey is to consider the most important prepurchase, purchase and post-purchase activities that are related to the product/service. Alternatively, the key season and off-season activities can be considered to represent the journey in a season-based view.

3. Identify the concerns: go through various concerns that the customer has, and which are supposed to be solved by the offerings in the chosen scope. Consider that concerns are influenced by the customer context. Context can include location, age group, time of the day/year, duration of owning the product, etc.

4. Analyze the identified (one several or all) concern in detail. Analyze detailed concerns for the chosen scenarios. Those can include Pains and Gains - specific thoughts, interests and issues that customers have in relation to a particular concern. Consider context to identify the most important pains and gains in relation to offerings in the chosen scope.

5. Go through proposed detailed concerns and suggest touchpoints - a suitable way to get in contact with the customer to resolve the identified concern. For instance, touchpoint can include a push-notification, In-App message, e-mail, phone call, social media post aimed at a specific customer group, etc. It is important to make sure that the touchpoint is relevant for the user context and can help to resolve one or several identified concerns.

6. Describe experiences that would characterize proposed touchpoints. This can help to choose between several touchpoints referring to the same offering and choose the one providing better experience. Use voting to choose the most appropriate alternatives (customer concern scenarios, touchpoints). Voting can help to identify the most important and timely option for further investigation or pilot implementation, from the modeling session participants point of view. Each participant can vote for defined number of proposed alternatives.

7. Review and refine. 


\subsubsection{Data-Driven Business Options}

Concepts incorporated: data-driven business options incorporate business actors, concerns, offerings, value and data objects (Figure 14.)

Objective: Data-driven business options is a focal area that helps to represent possible value adding use of the data produced by offerings (smart, connected products and services). This focal area enables representation of business actors and their concerns, and data that is produced by offerings that has value for the actors in focus.

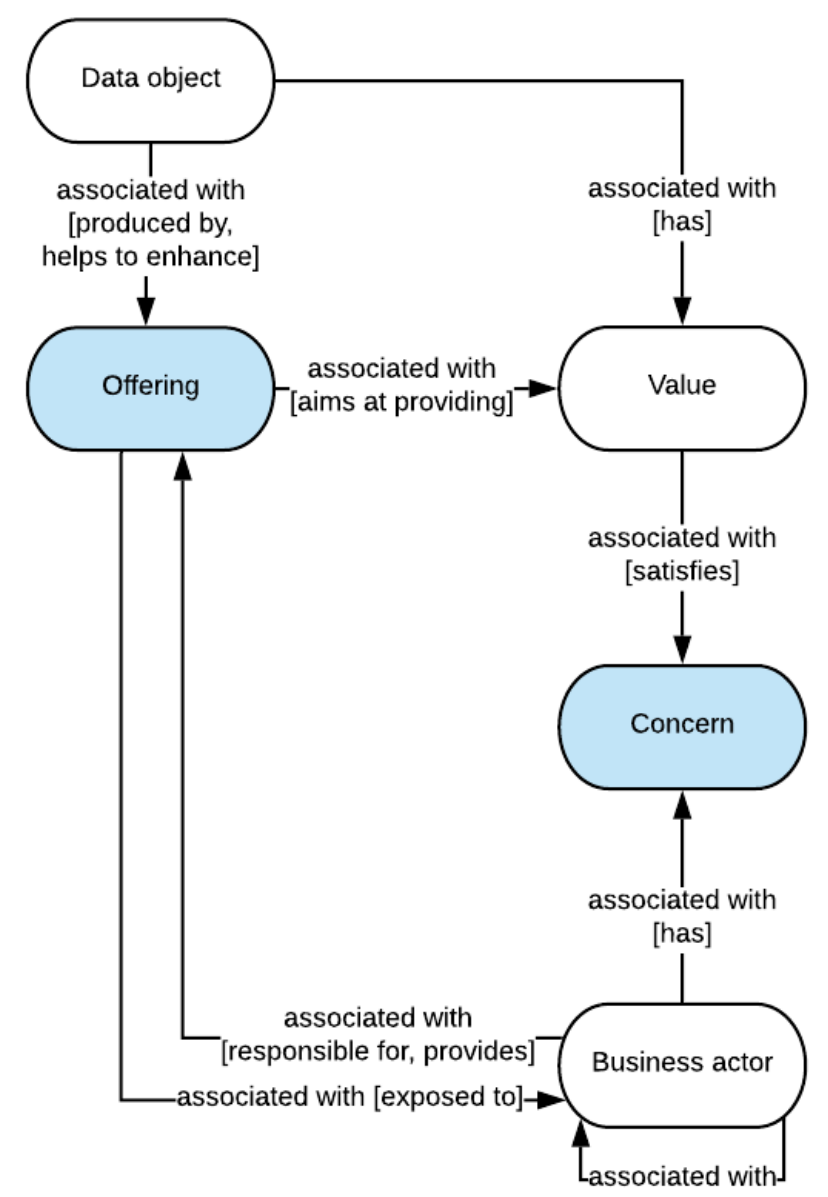

Figure 14. Business options focal area with included concepts

\section{Illustrative Example from the Case Study}

An example of data-driven business options is represented in Figure 15. The figure shows several communication episodes of business actors (Tractor owner, Service Center, Store) and offerings (Garden tractor, Toolshed App). Business actors have various concerns in relation to the offerings in focus. For instance, Tractor owner would like to know when to buy new spare parts and service the tractor. On the other hand, offerings produce data that can add value in relation to the concerns of the actors. Timely order of the spare parts and booking a service, sent from tractor to the Service Center and confirmed by the tractor owner, will have a significant perceived value in the described context. Product Info and Operational status (generated by the Toolshed app) would allow to form an order for the specified product and operational status (Value) and subsequently simplify the order process for both Tractor owner and the Store given their concerns. 


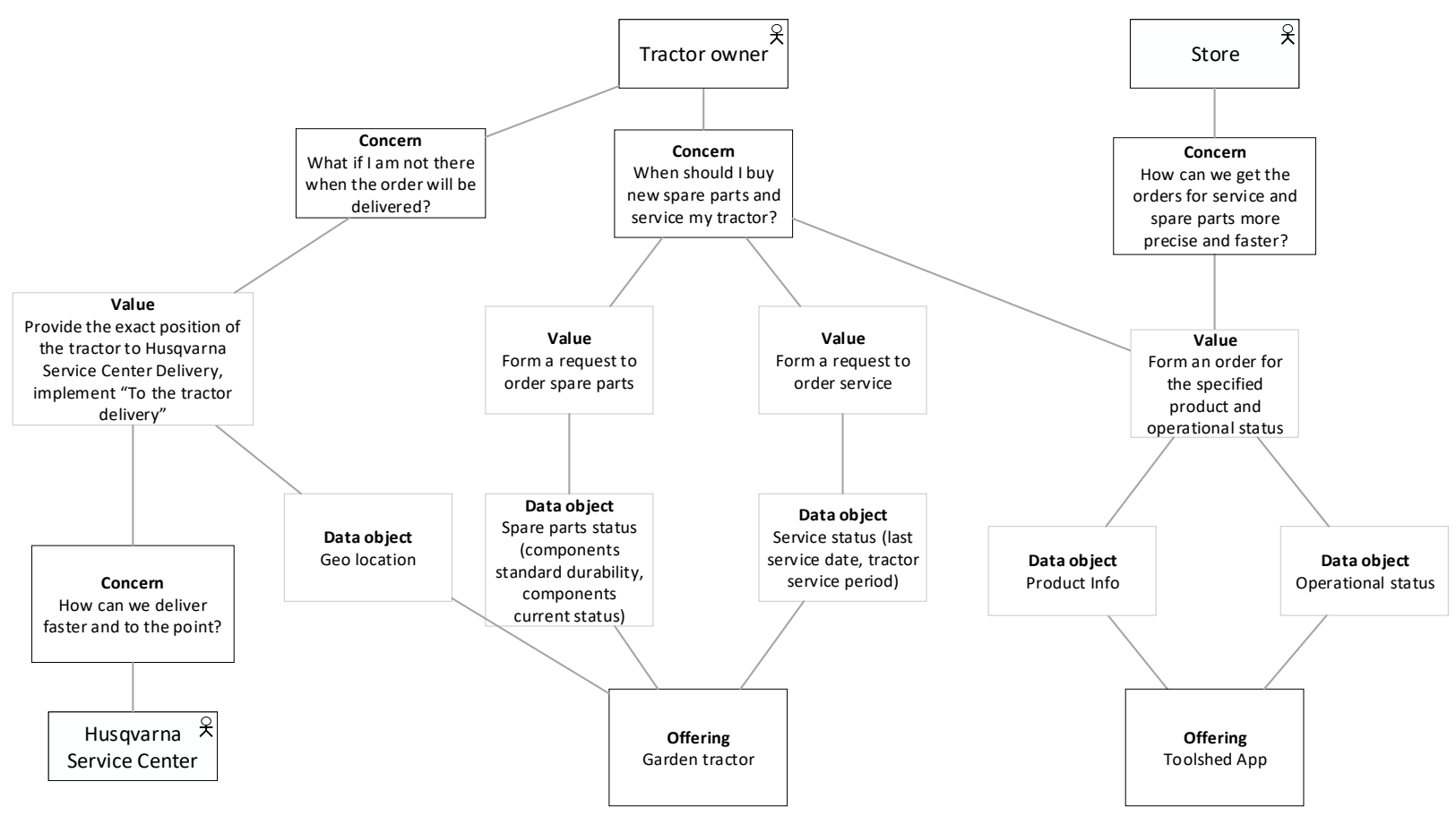

Figure 15. Data-driven business options - business actors and their concerns in relation to the offerings and the produced data

Procedures: The procedure for modeling of data-driven business options includes six steps and is based on the concepts that define this focal area (Figure 16).

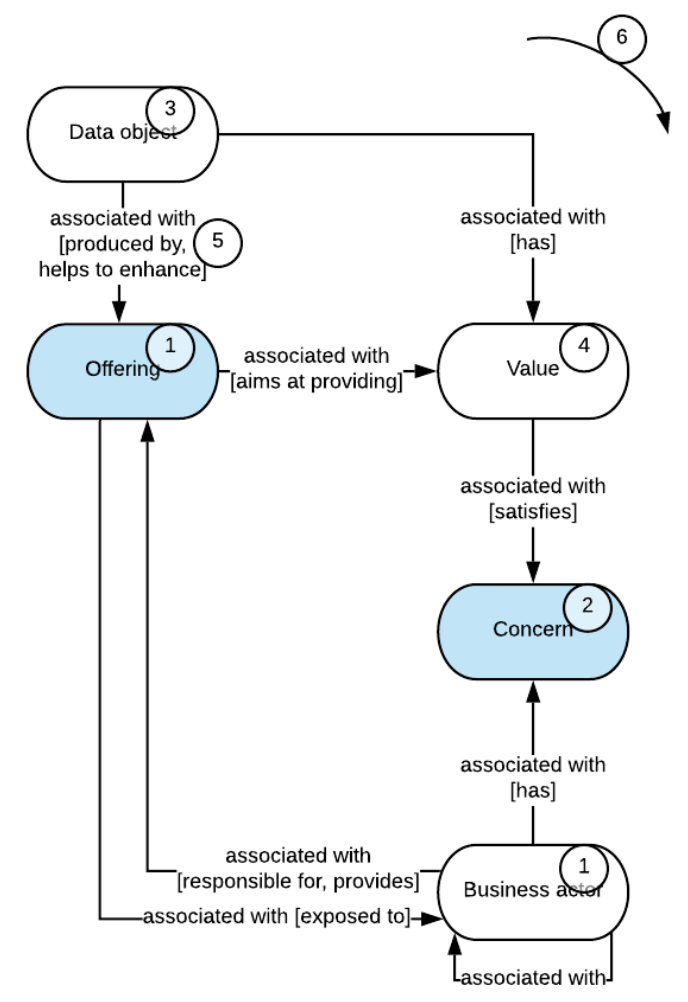

Figure 16. Procedures for modeling of business data-driven business options

1. Set the scope for analysis and identify the business actors to be focused on, and the offerings (products or services or their combination) relevant for their context. The focus can be set on an individual or a group of actors, and one or several offerings. 
2. For the specified business actors describe the concerns (a problem or need) in the scope of using the offerings. Consider that concerns are influenced by the actor context. Context can include location, age group, time of the day/year, duration of owning the product, etc.

3. Analyze and list data that is produced by the identified offerings. Consider and document data objects that have value in relation to the identified concerns of the business actors.

4. Analyze and describe the value of the identified data objects. Data objects can have value for solving one or several concerns of business actors.

5. Analyze whether the identified data objects and their value can become a part of the existing offerings or serve as a foundation for new offerings (products and services).

6. Review and refine.

\section{Validation of Approach and Selected Method Components}

The presented method components and the approach as a whole were validated through semistructured interviews with experts. The validation was divided into three evaluation meetings as discussed below.

\section{Evaluation meeting 1 with two experts}

This activity was designed to evaluate the concepts for product-IT inclusive EA. The descriptive evaluation through informed argument and scenarios in combination with evaluation through structural testing were applied. The set of concepts for Product-IT inclusive EA was demonstrated to the invited expert and discussed in detail. The concept model, see Figure 4 above, was presented, together with arguments for introducing new concepts. A number of scenarios was suggested, and the expert validated whether the proposed set of scenarios was sufficient to cover the domain in focus. Afterwards, the relationships between the specified concepts were validated, which served as a structural testing of the concept model in represented in Figure 4. Suggestions for improvements were documented and implemented through revision of the conceptual model(s).

Experts: two industrial experts in EA and digital product development, digital transformation and human-centered design.

Key contributions: evaluated set of concepts for product-IT inclusive EA.

\section{Evaluation meeting 2 with one expert}

This activity was designed to evaluate several dimensions of the product-IT inclusive EA approach: Concepts for product-IT inclusive EA, Focal areas for product-IT inclusive EA, Stakeholders for product-IT inclusive EA and Method for product-IT inclusive EA as a whole. The approach with these components was presented to the invited experts and discussed in detail. The descriptive evaluation was performed through presentation of scenarios together with arguments for each scenario. The expert evaluated whether the suggested set of concepts was sufficient to cover the domain in focus. In this evaluation meeting a set of stakeholders was also presented and discussed in detail with regards to the responsibilities and organizational affiliations. Suggestions for the improvements were documented and implemented in the method. The method was also validated in terms of structural coherence. The method component constituents were discussed with a special focus on the relationships between them. The method structure was also discussed in relation to the existing methods in EA field, comparing the aims of the methods and the choice of the method constituents to satisfy these aims.

Expert: industrial expert in Enterprise-IT implementation and integration, broad experience on digital transformation and shift from physical product production to smart, connected product production in traditional manufacturing companies.

Key contributions: validated set of concepts, focal areas and stakeholders for product-IT inclusive EA. 


\section{Evaluation meeting 3 with one expert}

This activity was designed to evaluate the product-IT inclusive EA approach as a whole including:

- Selected focal areas and method components for product-IT inclusive EA.

- Stakeholders for product-IT inclusive EA.

This was presented and discussed with the invited expert in detail to provide another perspective on the knowledge constructs.

The validation was performed through presentation of scenarios together with arguments for each scenario. The expert then validated whether the proposed set of concepts was sufficient to cover the domain in focus. In this evaluation meeting a set of stakeholders was also presented and discussed in detail with regards to the responsibilities and organizational affiliations. Suggestions for the improvements were documented and implemented in the final version of the method. To evaluate the method as a whole the structural testing of the presented method has been performed similarly to the Evaluation meeting 2.

Expert: academic expert in method development, EA and EAM, metamodel definition, constituents of methodological support in the EA field and digital transformation.

Key contributions: validated set of concepts, focal areas and stakeholders for product-IT inclusive EA.

To sum up these validation meetings, each validation activity resulted in several actions that were taken to improve the approach and the method. The refinement actions that took place included:

1. Accepting or refining the proposed naming of the constructs. Changing the name was suggested by the validation experts and implemented accordingly for several constructs among method requirements and concepts (constituent of the generated method).

2. Accepting or refining the presented meaning or definition of the constructs. Minor refinements of the meaning of several constructs were suggested and implemented for method requirements, concepts and focal areas (constituent in the generated method).

3. Accepting or refining the identified relationships between constructs. Refinements of the relationships between several constructs were suggested and implemented for relationships between concepts (constituent of the generated method).

4. Accepting or refining the stylistic details of the representation of constructs. Several stylistic changes were implemented for representation of the concepts and focal areas.

\section{Conclusions}

Based on an industrial case that illustrates the development of smart connected products and the creation of new kinds of business services, this article derives requirements for a product-IT inclusive EAM approach and addresses method support for product-IT inclusive business and application architectures. As a foundation for the method support, a meta-model is proposed which builds upon ArchiMate and integrates additional concepts required for representing product-IT and its use. The method as such consists of various components addressing the focal areas ecosystem of offerings, customer journey and data-driven business services. This method support can be integrated into TOGAF ADM in the phases B (Business Architecture) and C (Information Systems Architecture).

Application of the proposed method on two industrial cases showed its applicability and usefulness. One of the cases is included in this article in Section 4.1; and the excerpts from the case as examples are shown when introducing the method components in Section 5.3. Detailed information about the second case is included in [22]. Furthermore, expert evaluation confirmed that the method meets industrial demands. 
Future work will concern empirical and conceptulal perspectives. From an empirical perspective, application of the method in additional cases should be in focus to gain experiences and additional requirements for improving or revising the method. Application cases should primarily be enterprises with smart connected products. Other application fields with substantial product-IT should follow to check applicability of the method and adaptation needs. The conceptual perspective of future work should include the search for additional focal areas and their integration into the meta-model and method components. Examples could be service evolution or product-IT prepared for the third party components.

\section{References}

[1] M. Porter and J. Heppelmann, "How smart, connected products are transforming competition," Harvard Business Review, vol. 92, no. 11, pp. 64-88, 2014.

[2] T. Hess, C. Matt, A. Benlian, and F. Wiesböck, "Options for Formulating a Digital Transformation Strategy," MIS Quarterly Executive, vol. 15, no. 2, 2016.

[3] S. Buckl, T. Dierl, F. Matthes, and C. M. Schweda, "Building blocks for enterprise architecture management solutions," Working Conference on Practice-Driven Research on Enterprise Transformation, pp. 17-46, 2010. Available: https://doi.org/10.1007/978-3-642-16770-6_2

[4] T. Tamm, P. B. Seddon, G. G. Shanks, and P. Reynolds, "How does enterprise architecture add value to organisations?" Communications of the Association for Information Systems, vol. 28, pp. 141-168, 2011. Available: https://doi.org/10.17705/1CAIS.02810

[5] D. Simon, K. Fischbach, and D. Schoder, "Enterprise architecture management and its role in corporate strategic management," Information Systems and e-Business Management, vol. 12, no. 1, pp. 5-42, 2014. Available: https://doi.org/10.1007/s10257-013-0213-4

[6] F. Ahlemann, E. Stettiner, M. Messerschmidt, and C. Legner, Strategic enterprise architecture management: challenges, best practices, and future developments. Springer, 2012. Available: https://doi.org/10.1007/978-3642-24223-6

[7] M. Wißotzki, H. Koç, T. Weichert, and K. Sandkuhl, "Development of an enterprise architecture management capability catalog," International Conference on Business Informatics Research, pp. 112-126, 2013. Available: https://doi.org/10.1007/978-3-642-40823-6_10

[8] F. Rahimi, J. Gøtze, and C. Møller, "Enterprise architecture management: Toward a taxonomy of applications," Communications of the Association for Information Systems, vol. 40, no. 1, pp. 120-166, 2017. Available: https://doi.org/10.17705/1CAIS.04007

[9] The Open Group. The TOGAF Standard, Version 9.2. Van Haren Publishing, 2018.

[10] R. Harrison, TOGAF 9 Certified Study Guide. Van Haren, Publishing, 2011.

[11] H. Jonkers, E. Proper, and M. Turner, “TOGAF 9 and ArchiMate,” White Paper. The Open Group, 2009.

[12] The Open Group. ArchiMate $3.1 \quad$ Specification. $2019 . \quad$ Available: https://pubs.opengroup.org/architecture/archimate3-doc/toc.html

[13] P. Parviainen, M. Tihinen, J. Kääriäinen, and S. Teppola, "Tackling the digitalization challenge: How to benefit from digitalization in practice," International Journal of Information Systems and Project Management, vol. 5, no. 1, pp. 63-77, 2017.

[14] H. Hirsch-Kreinsen and M. ten Hompel, "Digitalisierung industrieller Arbeit: Entwicklungsperspektiven und Gestaltungsansätze,” Handbuch Industrie 4.0 Bd.3, pp. 357-376, 2017. Available: https://doi.org/10.1007/9783-662-53251-5_21

[15] B. J. Pine and J. H. Gilmore, "Welcome to the experience economy," Harvard Business Review, vol. 76, pp. 97-105, 1998.

[16] S. J. Berman and R. Bell, "Digital transformation: Creating new business models where digital meets physical," IBM Institute for Business Value, 2011.

[17] A. R. Hevner, S. T. March, J. Park, and S. Ram, "Design science in information systems research," MIS quarterly, vol. 28, no. 1, pp. 75-105.

[18] P. Johannesson and E. Perjons, An introduction to design science. Springer, 2014. Available: https://doi.org/10.1007/978-3-319-10632-8 
[19] K. Sandkuhl, J. Kaidalova, and U. Seigerroth, “Towards Integration Methods of Product-IT into Enterprise Architectures," IEEE 21st International Enterprise Distributed Object Computing Workshop (EDOCW), pp. 23-28, 2017. Available: https://doi.org/10.1109/EDOCW.2017.13

[20] J. Kaidalova, K. Sandkuhl, and U. Seigerroth, "How Digital Transformation affects Enterprise Architecture Management - A Case Study," International Journal of Information Systems and Project Management, vol. 6 , no. 3, pp. 5-18, 2018.

[21] J. Kaidalova, U. Seigerroth, and K. Sandkuhl, "Product-IT and Enterprise-IT integration in enterprise architecture management - Methodological perspective," 17th International Conference on Perspectives in Business Informatics Research (BIR), Workshop on Resilient Enterprise Architecture (REA), ceur-ws.org, vol. 2218, pp. 1-10, 2018.

[22] J. Kaidalova, Integration of Product-IT into Enterprise Architecture - A method for participatory Business and IT Alignment. PhD dissertation. University of Skövde (Sweden), 2019. ISBN 978-91-984918-3-8

[23] Z. Babar and E. Yu, "Enterprise Architecture in the Age of Digital Transformation," Advanced Information Systems Engineering Workshops, pp.438-443, 2015. Available: https://doi.org/10.1007/978-3-319-192437_40

[24] G. Goldkuhl, M. Lind, and U. Seigerroth, "Method integration: the need for a learning perspective," IEEE Proceedings-Software, vol. 145, no. 4, pp. 113-118. Available: https://doi.org/10.1049/ip-sen:19982197

[25] S. Davidson, E. Giesen, M. Harmer, and A. Marshall, "In or out? Succeeding in the ecosystem economy,” IBM Institute for Business Value, 2017.

[26] E. Pantano and M. Viassone, "Engaging consumers on new integrated multichannel retail settings: Challenges for retailers," Journal of Retailing and Consumer Services, vol. 25, pp. 106-114, 2015. Available: https://doi.org/10.1016/j.jretconser.2015.04.003

[27] A. Stein and B. Ramaseshan, "Towards the identification of customer experience touch point elements," Journal of Retailing and Consumer Services, vol. 30, pp.8-19, $2016 . \quad$ Available: https://doi.org/10.1016/j.jretconser.2015.12.001

[28] P. C. Verhoef, K. N. Lemon, A. Parasuraman, A. Roggeveen, M. Tsiros, and L. A. Schlesinger, "Customer experience creation: Determinants, dynamics and management strategies," Journal of Retailing, vol. 85, no. 1, pp. 31-41, 2009. Available: https://doi.org/10.1016/j.jretai.2008.11.001 